\title{
Importance of light, temperature, zooplankton and fish in predicting the nighttime vertical distribution of Mysis diluviana
}

\author{
Brent T. Boscarino ${ }^{1, *}$, Lars G. Rudstam ${ }^{1}$, June L. Eillenberger ${ }^{2}$, Robert O'Gorman ${ }^{3}$ \\ ${ }^{1}$ Cornell Biological Field Station, Department of Natural Resources, Cornell University, Bridgeport, New York 13030, USA \\ ${ }^{2}$ T7-020 Veterinary Research Tower, Cornell University, Ithaca, New York 14953, USA \\ ${ }^{3}$ United States Geological Survey, Great Lakes Science Center, Lake Ontario Biological Station, 17 Lake Street, Oswego, \\ New York 13126, USA
}

\begin{abstract}
The opossum shrimp Mysis diluviana (formerly M. relicta) performs large amplitude diel vertical migrations in Lake Ontario and its nighttime distribution is influenced by temperature, light and the distribution of its predators and prey. At one location in southeastern Lake Ontario, we measured the vertical distribution of mysids, mysid predators (i.e. planktivorous fishes) and mysid prey (i.e. zooplankton), in addition to light and temperature, on 8 occasions from May to September, 2004 and 2005. We use these data to test 3 different predictive models of mysid habitat selection, based on: (1) laboratoryderived responses of mysids to different light and temperature gradients in the absence of predator or prey cues; (2) growth rate of mysids, as estimated with a mysid bioenergetics model, given known prey densities and temperatures at different depths in the water column; (3) ratio of growth rates $(g)$ and mortality risk $(\mu)$ associated with the distribution of predatory fishes. The model based on light and temperature preferences was a better predictor of mysid vertical distribution than the models based on growth rate and $g: \mu$ on all 8 occasions. Although mysid temperature and light preferences probably evolved as mechanisms to reduce predation while increasing foraging intake, the response to temperature and light alone predicts mysid vertical distribution across seasons in Lake Ontario.
\end{abstract}

KEY WORDS: Mysis relicta $\cdot$ Modeling $\cdot$ Migration $\cdot$ Zooplankton $\cdot$ Vertical distribution $\cdot$ DVM

\section{INTRODUCTION}

Diel vertical migration (DVM) of invertebrates is a widespread phenomenon in both freshwater and marine systems, and probably evolved as a mechanism for maximizing food intake in upper, food-rich waters during periods of low risk from visual predators (Gliwicz \& Pijanowska 1988, Lampert 1993, Hays 2003). Most vertical movement into warmer, more productive waters to feed therefore occurs between dusk and dawn, when light levels are too low for efficient visual predation by planktivores. The vertical distribution of a migrating population at night is therefore either directly or indirectly influenced by the organisms' abiotic (i.e. light and temperature) and biotic (i.e. predator and prey distribution) environment.
The opossum shrimp Mysis diluviana (formerly $M$. relicta; Audzijonyte \& Väinölä 2005-hereafter referred to as 'mysids' unless otherwise noted), undergoes DVM in most of the deep lakes where it occurs, including Lake Ontario, one of the Laurentian Great Lakes of North America (Beeton \& Bowers 1982). In Lake Ontario, mysids ascend from their daytime benthic habitat into the water column at dusk, when they are both prey and competitors of planktivorous fishes such as alewife Alosa pseudoharengus and rainbow smelt Osmerus mordax (Johannsson et al. 2003).

The factors shaping the nighttime distribution of mysids are still poorly understood. Laboratory-derived temperature (Boscarino et al. 2007) and light preference (Boscarino et al. 2009) functions have been used to predict mysid vertical distributions when either tem- 
perature or light was the dominant environmental factor. However, little is known about how the relative influence of temperature or light on mysid distribution will vary across different seasons. Moreover, it is unclear as to how fish and zooplankton distributions modify the temperature and light preferences of mysids, because the preference functions derived by Boscarino et al. $(2007,2009)$ were developed in the laboratory in the absence of predators and prey.

In Lake Ontario, the zooplankton prey of mysids is concentrated in the upper portion of the water column (Gal et al. 2006) and their distribution may influence the nighttime habitat selection of mysids. Larsson (1997) demonstrated that a population of Daphnia pulex was distributed throughout different sections of an experimental chamber in direct proportion to the relative abundance of algal food resources, and argued that the distribution approximated an ideal free distribution (Fretwell \& Lucas 1969). Lampert et al. (2003) expanded this approach by predicting the distribution of a population of Daphnia hyalina $\times$ galeata in combined food and temperature gradients in large plankton towers based on growth rates at each depth in the column (ideal free distribution with costs model; Lampert et al. 2003). In the present study, we use a modified version of Lampert et al.'s (2003) model to predict mysid vertical distribution based on estimated growth rates of mysids at each depth as a function of both food availability and temperature.

In addition to growth rate, mortality risk is commonly invoked in models of vertical migration. The distribution of alewives, the most abundant fish in Lake Ontario (Owens et al. 2003), changes seasonally (Mills et al. 1992, Rand et al. 1994) and could also influence mysid nighttime distribution, particularly because alewives feed at night (Janssen \& Brandt 1980) and are able to feed in total darkness (Janssen 1990, Janssen et al. 1995). Mysids may respond to predation risk by avoiding waters inhabited by alewives, because they sense fish kairomones (Hamrén \& Hansson 1999, Gal et al. 2004, Boscarino et al. 2007).

The potential effect of both predator and prey distributions can be combined by calculating the ratio of gain (typically estimated by either gains in growth, $g$, or in foraging, $f_{i}$ e.g. Werner \& Gilliam 1984) to mortality risk $(\mu)$. Ratios between gain and risk have been used to predict both the timing and amplitude of migration in a variety of fish (Scheuerell \& Schindler 2003, Jensen et al. 2006) and invertebrate species (Fiksen 1997, Liu et al. 2003). These models assume that an organism will always choose a depth that minimizes the ratio between growth gains and perceived mortality risks. In order to predict entire distributions based on this ratio, one needs to either (1) have prior knowledge of an organism's preference for different combinations of $g: \mu$, or (2) assume that a population is distributed in direct proportion to its $g: \mu$ profile and test this assumption empirically. Given the absence of laboratory-derived data on the preference of mysids to different $g$ : $\mu$ ratios, we compared predictions based on the magnitude of difference between risk and gain at each depth to observed distributions of mysids in the field.

We tested 3 different models of the nighttime vertical distribution of mysids, based on: (1) laboratory-derived light and temperature preferences (e.g. Gal et al. 2004, Boscarino et al. 2007, 2009), (2) mysid growth rate (e.g. Lampert et al. 2003), and (3) ratio between growth rate and mortality risk. We elected not to test a model based on mortality risk alone, since alewife densities drop markedly beneath the thermocline in the offshore part of Lake Ontario (Gal et al. 2004), and this would ensure minimization of predation pressure at the deepest depth evaluated if foraging gains in shallower waters were not considered. We have already shown that this is an unrealistic prediction for mysids in Lake Ontario (Gal et al. 2004, 2006). The objective of this study is to test whether mysid distribution can be predicted based on adult light and temperature preferences alone, or whether predator and prey distributions must be invoked to predict their distribution. We compare predictions made by all 3 models to observed mysid vertical distributions measured on 8 nights in southeastern Lake Ontario in 2004-2005.

\section{MATERIALS AND METHODS}

Sampling design. We conducted 8 research cruises on Lake Ontario on May 19, August 16, August 27, and September 30 in 2004 and May 5, June 20, July 7 and September 27 in 2005 aboard the United States Geological Survey's RV 'Kaho' (we refer to these sampling nights by the date on which we left the harbor, even though we did not return until the following morning at dawn). Sampling dates were selected to measure the nighttime distribution of mysids under 'high' and 'low' light intensities (full moon or new moon) in each of 3 seasons (spring, summer, fall). During most cruises we (1) used acoustics data with at least 1 or some combination of 3 different frequencies $(70,123$ and $430 \mathrm{kHz}$ ) to determine the vertical distribution of mysids and fishes (Table 1); (2) deployed plankton, mid-water trawl, and gill nets to identify acoustic targets and capture fishes for diet analysis; (3) collected zooplankton at discrete depths to determine zooplankton vertical distribution; and (4) collected depth profiles of light and temperature with a combination of a SeaBird instrument and a high-sensitivity light meter. All night sampling was conducted at or near a $170 \mathrm{~m}$ depth station located $11.1 \mathrm{~km}$ NNW of Oswego, New York (Table 1). 
Table 1. Sampling times, dates, acoustics equipment and calibration settings used in analysis. Detection limits for mysids with $430 \mathrm{kHz}$ and $123 \mathrm{kHz}$ represent the depth at which background noise is equal to a density of 5 mysids $\mathrm{m}^{-3}$. Detection limits for fish at $70 \mathrm{kHz}$ and $123 \mathrm{kHz}$ represent the depth at which background noise is equal to the backscattering produced by a single alewife with an average target strength of $-54 \mathrm{~dB}$. Noise: volume backscattering strength $\left(\mathrm{S}_{\mathrm{v}}\right)$ at $1 \mathrm{~m}$ depth

\begin{tabular}{|c|c|c|c|c|c|c|c|}
\hline \multirow[t]{2}{*}{ Year } & \multirow[t]{2}{*}{ Date } & \multirow[t]{2}{*}{ Time of day } & \multirow{2}{*}{$\begin{array}{l}\text { Bottom depth } \\
(\mathrm{m})\end{array}$} & \multirow{2}{*}{$\begin{array}{l}\text { Frequency } \\
\quad(\mathrm{kHz})\end{array}$} & \multirow{2}{*}{$\begin{array}{l}\text { Noise at } 1 \mathrm{~m} \\
(\mathrm{~dB})\end{array}$} & \multicolumn{2}{|c|}{ Detection limit (m) } \\
\hline & & & & & & Mysids & Fishes \\
\hline \multirow[t]{4}{*}{2004} & 19 May & $3: 37-3: 55$ & $120-170$ & 430,70 & $-116.7^{a},-119.0^{b}$ & 58 & 93 \\
\hline & 16 Aug & $2: 44-4: 00$ & $116-170$ & 430,70 & $-117.2^{\mathrm{a}},-125.0^{\mathrm{b}}$ & 68 & 133 \\
\hline & 27 Aug & $1: 29-2: 52$ & $110-170$ & 430,70 & $-116.4^{\mathrm{a}},-124.5^{\mathrm{b}}$ & 64 & 127 \\
\hline & $30 \mathrm{Sep}$ & $0: 44-1: 39$ & $150-170$ & 430,70 & $-117.0^{\mathrm{a}},-115.2^{\mathrm{b}}$ & 67 & 75 \\
\hline \multirow[t]{4}{*}{2005} & 5 May & $3: 14-3: 39$ & $116-170$ & 430,70 & $-116.9^{\mathrm{a}},-113.0^{\mathrm{b}}$ & 67 & 66 \\
\hline & 20 June & $22: 18-23: 41$ & $165-170$ & 123 & $-134.7^{\mathrm{c}}$ & Bottom & Bottom \\
\hline & 7 July & $22: 00-23: 45$ & $165-170$ & 123 & $-135.9^{c}$ & Bottom & Bottom \\
\hline & 27 Sep & $12: 00-3: 12$ & $165-170$ & 123 & $-131.0^{c}$ & Bottom & 165 \\
\hline
\end{tabular}

Temperature and light profiles. Temperature data were collected at $1 \mathrm{~m}$ intervals with a SeaBird profiler lowered to the bottom. In 2004, light extinction was obtained with a PAR light meter that integrated the total light available between 400 and $700 \mathrm{~nm}$ (PAR range). We measured light extinction during the day, because our SeaBird was not sensitive enough to measure light at night. For each sampling date, we calculated the average extinction coefficient values $\left(\mathrm{k}_{\mathrm{PAR}}, \mathrm{m}^{-1}\right)$ at $20 \mathrm{~m}$ intervals and used the relationships in Jerome et al. (1983) to calculate wavelength-specific extinction coefficients for each $20 \mathrm{~m}$ depth interval of the water column (see Gal et al. 1999, 2004). These extinction coefficients were then combined with the calculated nighttime surface irradiance (see below), to derive wavelength-specific irradiance values at $1 \mathrm{~m}$ depth intervals in the water column at night. These calculations assumed a moonlight spectrum at the surface (see Gal et al. 1999). Following Gal et al. (1999, 2004) and Boscarino et al. (2007), we calculated light at depth in 'mylux' by applying the normalized mysid visual sensitivity curve (ranging from 0 to 1 after Gal et al. 1999) to the estimated total amount of light available at each depth and wavelength (Gal et al. 1999). The concept of mylux units is similar to the concept behind lux in that it is a scale adjusted to an organism's relative spectral sensitivity. Mysid visual pigments retain the same absorbance characteristics regardless of season or developmental stage (Lindström \& Nilsson 1988), so we assumed that all mysids had identical spectral sensitivities.

Surface irradiance in lux was predicted with the moonlight illuminance modeling program of Janiczek \& DeYoung (1987) for all full moon nights. The Janiczek \& DeYoung model is not capable of predicting light levels at new moon, and we therefore used values reported by Austin et al. (1976) for new moon nights and times when the moon was below the horizon. These 2 studies yield illuminance values within a factor of 2 of each other when moon phase and zenith angles are the same (B. T. Boscarino, unpubl.). All predicted surface values, in lux, can be converted to mylux using the conversions of Gal et al. (1999), which are valid for a moonlight spectrum: 1 mylux $=175$ lux $=0.51 \mathrm{~W} \mathrm{~m}^{-2}$.

In 2005, we collected light data using a specially designed light meter ( $\mathrm{mk} 9$ archival tag, Wildlife Computers), which we equipped with a Rosco ${ }^{\circledR}$ Roscolux ${ }^{\circledR}$ filter \# 91 (peak transmission between 510 and $520 \mathrm{~nm}$ ) that closely resembles the spectral sensitivity of the mysid eye (wavelength of maximum absorbance, $\lambda_{\max }=$ $520 \mathrm{~nm} ;$ Gal et al. 1999). Differences in $\lambda_{\max }$ between the filter and the mysid eye pigment were reconciled by applying a correction factor to measurements obtained with the mk9 tag, which thus measured light in units directly proportional to mylux (see Boscarino et al. 2009).

The mk9 tag was calibrated to a Gamma Scientific light source, which has an accuracy of $\pm 2 \%$ of the international light calibration transfer standards $( \pm 2 \%$ for NIST transfer). This tag is capable of storing light levels in millisecond intervals, and this allowed us to measure light at $1 \mathrm{~m}$ depth intervals throughout the water column.

Because we did not have the mk9 tag in 2004, we compared light level estimations using both techniques in 2005 to check for any inconsistencies between the 2 methods. Differences were less than a factor of 5 , even as far as $50 \mathrm{~m}$ below the surface. These discrepancies would result in a maximum change of $5 \mathrm{~m}$ in the predicted peak mysid distribution on June 20, 2005 (differences on all other dates were $<2 \mathrm{~m}$ ). Although we consider the mk9-derived light profiles to be a better representation of the light perceived by mysids, we did not adjust the 2004 light profiles, because there were no consistent directional differences between the 2 methods in the 2005 surveys.

Hydroacoustic data. Mysid distributions: Mysid vertical distributions were measured by hydroacoustics at 
night along a transect from the $170 \mathrm{~m}$ station to a bottom depth no less than $110 \mathrm{~m}$ (2004) or while stationary at the $170 \mathrm{~m}$ station (2005) (Table 1). Ship lights were minimized during data collection; 2 transducers were mounted on a tow body positioned $5 \mathrm{~m}$ away from the starboard side of the boat and towed with the transducer face at a depth of $1.5 \mathrm{~m}$. The tow body was balanced to remain horizontal when the ship was stationary. We used a $70 \mathrm{kHz}$ unit $\left(11.4^{\circ}\right.$ beam width; Simrad EY500 split beam) and a $430 \mathrm{kHz}$ unit ( $6^{\circ}$ beam width; Biosonics DtX single beam) in 2004. In 2005, the $70 \mathrm{kHz}$ unit was replaced by a $123 \mathrm{kHz}$ unit $\left(7.8^{\circ}\right.$ beam width; Biosonics DtX split beam). We initially expected to use the $430 \mathrm{kHz}$ data for mysids following Gal et al. (2004) and the lower frequency (70 or $123 \mathrm{kHz}$ ) for fishes. Rudstam et al. (2008a) showed that mysid target strength (TS) is about $5 \mathrm{~dB}$ higher at $430 \mathrm{kHz}$ than at $123 \mathrm{kHz}$. However, the higher TS of a mysid at $430 \mathrm{kHz}$ does not compensate for the increased sound absorption at the higher frequencies, and frequencies between 120 and $200 \mathrm{kHz}$ are better for detecting mysids in deep water than $430 \mathrm{kHz}$ (Rudstam et al. 2008a). All data analysis was done with EchoView 3.4.

The $430 \mathrm{kHz}$ single beam unit was calibrated by the manufacturer on April 4, 2004, May 25, 2005 and February 20, 2007; source levels ranged from 218.55 to $218.18 \mathrm{~dB}$ and no additional corrections were applied to the $430 \mathrm{kHz}$ data. The $123 \mathrm{kHz}$ unit was calibrated by the manufacturer in May 2005, and was within $0.1 \mathrm{~dB}$ of the previous calibration in October 2005 using a $-40.4 \mathrm{~dB}$ standard copper sphere. The $70 \mathrm{kHz}$ unit was calibrated before each survey with a standard $-39.2 \mathrm{~dB}$ copper sphere and adjusted as necessary. Calibration varied less than $\pm 1 \mathrm{~dB}$ on this unit during 2004 and 2005. All acoustics data were collected at a pulse duration of $0.6 \mathrm{~ms}$ and a ping rate of $1 \mathrm{ping} \mathrm{s}^{-1}$. Biosonics data (123 and $430 \mathrm{kHz}$ ) were collected with a square threshold of $-130 \mathrm{~dB}$; no lower threshold was applied to the $70 \mathrm{kHz}$ data.

Hereafter, we refer to any acoustic scattering layer as the 'mysid layer' if the layer (1) was not apparent before sunset, (2) stabilized within a distinct depth range within 1 to $2 \mathrm{~h}$ after sunset, and (3) was no longer observed at depths $<50 \mathrm{~m}$ in the water column at dawn; these observations are consistent and unique to mysids in Lake Ontario (Johannsson et al. 2003). Net samples (conical opening and closing net, $1 \mathrm{~m}$ diameter, mesh size: $1 \mathrm{~mm}$ ) were obtained at the $170 \mathrm{~m}$ station on each night to confirm that this scattering layer was primarily composed of mysids. Replicate tows were made 'above', 'through', and 'below' the mysid layer after visual inspection of acoustic echograms. All sampling was done under minimal red light. Mysids were preserved in $95 \%$ alcohol in the field and later enumerated and measured in the laboratory.
Lengths were converted to biomass using a length to dry weight regression originally derived by Johannsson et al. (1995) and modified by Rudstam et al. (2008b):

$$
\ln \mathrm{DW}=-12.55+2.72 \ln \mathrm{L}
$$

where DW is dry wt in $\mathrm{g}$, and $\mathrm{L}$ is length from the tip of the rostrum to the cleft of the telson in $\mathrm{mm}$. Biomass values were converted to wet weight (WW; Morgan 1976), as the bioenergetics applications used in this study are based on mysid WW (Rudstam 1989; see present study, 'Materials and methods-ModelsGrowth $(g)$ model'). Total mysid abundance (ind. $\mathrm{m}^{-2}$ ) was estimated by dividing the total number of mysids caught in a net haul by the area of the net opening. Mysid net tows were not taken on August 16, 2004, due to time constraints.

Fish echoes were defined as data pixels with echo returns $>-60 \mathrm{~dB}$ in the uncompensated TS domain of the 70 or $123 \mathrm{kHz}$ data and the corresponding pixels were replaced by 'no data' tags in the 430 or $123 \mathrm{kHz}$ dataset. We used this threshold for all surveys based on inspection of echograms. We removed ambient noise by subtraction of the expected noise level at each depth calculated from the noise levels at $1 \mathrm{~m}$ (Korneliussen 2000). The depth limit for detection of a density of 5 mysids $\mathrm{m}^{-3}$ was calculated using a TS of a single mysid of $-80.1 \mathrm{~dB}$ at $430 \mathrm{kHz}$ and $-84.9 \mathrm{~dB}$ at $123 \mathrm{kHz}$ (12 mm mysid; Rudstam et al. 2008a), sound absorption, and measured noise level (Table 1). Acoustic data from the mysid layer was exported at $1 \mathrm{~m}$ intervals after removing noise and contributions from fishes. Sound scattering from above the mysid layer was excluded, as that depth layer includes backscattering from other zooplankton and from larval fishes that would not have been removed by the fish exclusion threshold chosen here. The method is described in detail in Rudstam et al. (2008b).

Fish densities: These were obtained for the same transects and time periods as the mysid densities with the 70 or $123 \mathrm{kHz}$ data. We first applied a data threshold in the uncompensated TS data of $-60 \mathrm{~dB}$ and converted this filtered dataset to volume backscattering strength $\left(\mathrm{S}_{\mathrm{v}}\right)$. This will exclude most mysid backscattering (see above) and include most backscattering from fishes with a TS $>-54 \mathrm{~dB}$ (see Rudstam et al. 2008b). Fish density at depth was calculated by scaling the volume backscattering coefficient $\left(\mathrm{s}_{\mathrm{v}}\right)$ with the in situ backscattering cross section $\sigma_{\mathrm{bs}}$ calculated separately for the epiliminion and meta/hypolimnion (the mysid layer) for targets $>-54 \mathrm{~dB}$. Fish density was calculated for each $2 \mathrm{~m}$ depth interval from $2 \mathrm{~m}$ below the transducer (depth of $3.5 \mathrm{~m}$ in most surveys and $2.5 \mathrm{~m}$ in June 2005) to $2 \mathrm{~m}$ above the bottom of the lake. Total fish abundance in ind. ha ${ }^{-1}$ was calculated for depths 
from 3 or $4 \mathrm{~m}$ to $60 \mathrm{~m}$. We summed all estimates down to $60 \mathrm{~m}$ so that we could make direct density comparisons between sampling dates that may have had different detection limits. The depth of maximum mysid density was shallower than $60 \mathrm{~m}$ on all sampling dates.

Fish species identification was verified based on either mid-water trawls or gillnetting conducted at each station, with the exception of May 19, 2004 (nets not available) and July 7, 2005 (when emphasis was on mysid TS estimations). Each gillnet set consisted of a series of 7 separate $3 \mathrm{~m}$ wide by $20 \mathrm{~m}$ deep nets, each tied together by a $15 \mathrm{~m}$ rope. Each net had a different mesh size $(6.25,8,10,12.5,15,18.5$ and $25 \mathrm{~mm}$ bar mesh). This range of mesh sizes catches alewife from 50 to $250 \mathrm{~mm}$ total length with similar efficiencies (Warner et al. 2002). Each gillnet set was allowed to drift several hundreds of meters away from the boat for at least $5 \mathrm{~h}$. Gillnets were suspended between 15 and $35 \mathrm{~m}$ in the water column. Decisions on the depth of the set were made prior to each sampling night and were based on the likely depth ranges associated with the upper edge and peak of the main mysid scattering layer. The fishes were identified to species, their depth in the net was noted, and total length was measured to the nearest $\mathrm{mm}$. We also determined presence/absence of mysids in the gut contents of all fishes caught. The number of fishes caught per hour of gillnet set was also recorded, to compare catch per hour across dates in which gillnets were used. Gillnet and trawl catches (see below) were not used to derive overall abundance estimates.

Mid-water trawling was conducted on June 20, 2005, and September 27, 2005. Trawls were conducted through the mysid layer, as determined by visual inspection of echograms. Trawls through the mysid layer were between 23 and $51 \mathrm{~m}$ depth on June 20, 2005, and between 22 and $60 \mathrm{~m}$ depth on September 27, 2005. Fishes caught in each trawl haul were identified to species, enumerated, measured (nearest mm total length), and evaluated for presence/absence of mysids in the gut. The number of alewives caught per hour trawled was also recorded to compare abundance between the 2 dates in which mid-water trawling was used.

Zooplankton distribution. Samples were obtained at the $170 \mathrm{~m}$ station with a submersible pump (Dayton ${ }^{\circledR}$ submersible sump pump) for all dates in 2004 and on the May, June and October 2005 cruises. We did not take zooplankton pump samples during the July 2005 sampling trip, due to time constraints, and instead relied on 2 replicate stratified net tows for every $10 \mathrm{~m}$ depth interval down to a depth of $50 \mathrm{~m}$. Pump samples on all other nights were taken at $2 \mathrm{~m}$ intervals from the surface down to $30 \mathrm{~m}$ (the length of our hose) and at $4 \mathrm{~m}$ intervals on the way back to the surface; $100 \mathrm{l}$ of water were strained through a $64 \mu \mathrm{m}$ mesh net for each depth interval and samples were immediately preserved in $95 \%$ ethanol.

Stratified net tows $(0.5 \mathrm{~m}$ diameter opening/closing, $64 \mu \mathrm{m}$ mesh nylon net) through the 30 to $40 \mathrm{~m}$ and 40 to $50 \mathrm{~m}$ depth strata were also collected in 2005 to assess zooplankton community structure at depths $>30 \mathrm{~m}$. These net tows were not taken in 2004 and we assumed the density of zooplankton in the deepest depth sampled $(30 \mathrm{~m})$ was representative of depths down to $50 \mathrm{~m}$ (see 'Discussion'). Because pump and net sampling may have different sampling efficiencies for size groups and species (Johannsson et al. 1992, Masson et al. 2004), we performed net tows through the top $22 \mathrm{~m}$ of the water column on September 27, 2005 to compare the species composition and absolute density estimates obtained by the 2 gears.

All zooplankton were categorized into 9 major groups: daphnids, nauplii, Cercopagis pengoi, Bythotrephes longimanus, cyclopoid copepods, calanoid copepods, bosminids, Holopedium gibberum and Limnocalanus macrurus. We counted and measured at random 100 or more organisms from each sample using a compound microscope at 10 to $40 \times$ magnification. C. pengoi and $B$. longimanus were sieved out separately from smaller zooplankton and the entire sample was counted, given these larger organisms' propensity for clumping together and biasing subsamples. We used length:dry weight (L:DW) regression equations previously used for Lake Ontario zooplankton (see Benoit et al. 2002) to estimate total zooplankton biomass and the biomass of each group for each depth interval. This procedure follows the standard methods used by the Lake Ontario biomonitoring program (e.g. Warner et al. 2006). Biomass was averaged down to $30 \mathrm{~m}$ to arrive at a mean zooplankton biomass estimate for each night.

Models. Temperature-light model (TLM): We used the model of Boscarino et al. (2009) to predict the vertical distribution of mysids on each of the 8 nights. This model uses laboratory-based light and temperature preferences, derived in the absence of predator or prey cues, to yield an index of habitat preference for each $1 \mathrm{~m}$ depth interval given ambient temperature $\left({ }^{\circ} \mathrm{C}\right)$ and light levels (mylux) by depth. The 2 preference curves are assumed to be independent and have equal weight - assumptions based on experiments by Boscarino et al. (2009). The probability of finding a mysid at depth $z$ $\left[P_{\mathrm{TLM}}(z)\right]$ and the distribution of mysids in the water column can be described by:

$$
P_{\mathrm{TLM}}(z)=\frac{h\left(L_{z}\right) \times f\left(T_{z}\right)}{\sum_{z=1}^{z_{\max }} h\left(L_{z}\right) \times f\left(T_{z}\right)}
$$

where $f\left(T_{z}\right)$ and $h\left(L_{z}\right)$ represent the value of the temperature and light functions at depth $z$, respectively, and $z_{\max }$ is the maximum depth included in the analy- 
sis. The denominator is the sum of this product over all depths considered. The light preference function $h(L)$ and the temperature preference function, $f(T)$, are defined in Boscarino et al. $(2007,2009)$ and reproduced here:

$$
\begin{aligned}
& h(L)=0.10 \text { for } L \leq 10^{-10} \text { and } \\
& h(L)=\mathrm{e}^{-0.5\left\{\frac{\log _{10}(L)-[-7.53]}{0.76}\right\}^{2}} \text { for } L>10^{-10} \\
& f(T)=\mathrm{e}^{-0.5\left\{\frac{\ln (T)-[\ln (6.07)]}{0.23}\right\}^{2}}
\end{aligned}
$$

Direct comparisons were made between differences in predicted versus observed depth of peak mysid density, whereas the percent overlap between predicted and observed mysid distributions was assessed by the Czekanowski index of overlap: $\mid 1-(0.5 \times \Sigma$ (observed predicted) $\mid \times 100$ (Feinsinger et al. 1981). A perfect fit of predicted to observed distributions would therefore result in an index of $100 \%$.

Growth (g) model: The second model is based on calculating the estimated growth rate of an individual mysid at each depth of the water column and assumes that mysids are distributed in proportion to their depthspecific growth rates (e.g. Lampert et al. 2003). Growth rate was estimated as the difference between energy intake and physiological costs. Energy intake is based on a functional response model (Cooper \& Goldman 1980) modified by temperature (Rudstam et al. 1999). Physiological costs were calculated for a mysid with a length of $12 \mathrm{~mm}$ and are temperature dependent following a bioenergetics model for mysid growth and consumption by Rudstam (1989), which was independently validated for Mysis relicta by Chipps \& Bennett (2002).

Depth-specific consumption was estimated by applying the Type I functional response curve published in Cooper \& Goldman (1980, their Fig. 2) for Mysis relicta feeding on Epischura nevadensis in the laboratory. Applying a Type I functional response curve to our field data is reasonable, given the low to medium zooplankton densities observed in this study and others (e.g. Johannsson et al. 1994). Prey densities reported in Cooper \& Goldman (1980) were converted into dry weight (DW) to derive a functional response equation relating prey biomass to the total zooplankton biomass consumed per day $(C)$. The regression was forced through the origin, so that feeding rate would be zero if no prey were available. This relationship is expressed as follows:

$$
C=2 \times 10^{-5} \times(\text { prey biomass }) ; \mathrm{r}^{2}=0.99, \mathrm{n}=5
$$

where $C$ is consumed biomass (g zooplankton DW) per (g mysid WW) $\mathrm{d}^{-1}$, and prey biomass is zooplankton DW (in $\mu \mathrm{g}^{-1}$ ). This consumption relationship was evaluated for all measured prey densities and temperatures from the surface down to $50 \mathrm{~m}$ at $1 \mathrm{~m}$ intervals on each of the 8 nights sampled. Because ingestion and gut evacuation rates vary with temperature, we applied a temperature-specific multiplier (based on the feeding rates of mysids on Artemia spp. at different temperatures; Rudstam et al. 1999, Gal et al. 2004) to account for variations in food intake rate with temperature. The peak of this feeding curve occurs at $9^{\circ} \mathrm{C}$, representing a temperature-specific multiplier of 1 . The multiplier at other temperatures ranged from 0 to 1 following the curve of Gal et al. (2004). Thus, total consumption at any depth was calculated as the functional response (dependent on prey abundance) and this multiplier (dependent on temperature). Although feeding rate may decrease in the presence of conspecifics (Hansson et al. 2001), we did not include this effect in the model. Caloric intake was calculated from zooplankton biomass consumed using a value of 5411 cal per g DW (Johannsson et al. 1994).

Each depth-specific growth value was then used to construct a vertical growth profile from the surface down to $50 \mathrm{~m}$ on each of the sampling nights. The probability of observing a mysid at any given depth $z_{\text {, }}$ $\left[P_{g}(z)\right]$, is described by the following equation:

$$
P_{g}(z)=\frac{g(z)}{\sum_{z=1}^{z_{\max }} g(z)}
$$

where $g(z)$ represents the value of the growth function at depth $z$, and $z_{\max }$ is the maximum depth included in the analysis. Direct comparisons were made between differences in predicted versus observed depths of peak mysid density and the percent overlap between predicted and observed mysid distributions was assessed by the Czekanowski index.

Growth:mortality risk (g: $\mu)$ model: We modeled the vertical change in the ratio of estimated growth rate of mysids to the perceived mortality risk-hereafter referred to as the ' $g: \mu$ model' - with respect to temperature, predator abundance and prey biomass at $1 \mathrm{~m}$ depth increments in the water column for each of the 8 sampling nights. Mortality risk is modeled as fish abundance multiplied by a light dependent function relating the proportion of fishes that are feeding to ambient light levels.

Because no data currently exist on alewife reaction distance at the low light levels experienced by fishes that are feeding in the mysid layer at night, mortality risk was estimated by deriving a best-fit linear equation through data for a related clupeid (herring Clupea harengus) in Batty et al. (1990, their Fig. 2A); the figure describes the relationship between light levels (0 to 270 lux) and the proportion of herring feeding on zooplankton in the laboratory. We converted all lux values presented by Batty et al. (1990) to mylux using the conversions of Gal et al. (1999) and log-transformed all light levels to linearize the relationship. A third-order 
polynomial curve was fitted to the data describing the proportion of fishes that are feeding as a function of log-transformed light values, between $10^{-1.24}$ to $10^{-5.24}$ mylux, such that the sums of squares of differences between observed and predicted proportions of fishes that are feeding were minimized (third-order polynomial regression; Microsoft Excel Version 12.0; adjusted $r^{2}=0.72, n=31$ ). For all light levels at least one order of magnitude lower than the visual threshold of $10^{-3}$ lux, (or $10^{-5.24}$ mylux), the function was set to 0.1 , which represents the proportion of fishes that are feeding in complete darkness. The equation for this lightdependent multiplier, $n(L)$, evaluated at all light levels $L<0.058$ mylux $[\log (L)<-1.24]$ is:

$n(L)=-0.009(\log L)^{3}-0.0979(\log L)^{2}-0.1777(\log L)+$ 0.6181

for $-6.24<\log L<-1.24$.

$n(L)=0.10$ for $\log L \leq-6.24$

We assumed mortality risk $\mu$ to be proportional to the density of fishes $\left(\rho\right.$, in ind. $\mathrm{m}^{-3}$ ) multiplied by the proportion of fishes that are feeding at light level $L[n(L)]$, such that:

$$
\mu(\rho, L)=\rho n(L)
$$

Growth:mortality risk ratios were then constructed by dividing the value of the growth function $g$, by the value of the risk function $\mu$, evaluated for each depth $z$ in $1 \mathrm{~m}$ depth intervals. Therefore, the probability of finding a mysid at any depth $\mathrm{z}\left[P_{g: \mu}(z)\right]$, given all available depths $\left(1, z_{\max }\right)$ equals:

$$
P_{g: \mu}(z)=\frac{\frac{g(z)}{\mu(z)}}{\sum_{z=1}^{z_{\max }} \frac{g(z)}{\mu(z)}}
$$

Comparisons with observations were done in the same manner as the other 2 models.

\section{RESULTS}

\section{Light and temperature conditions}

Average $\mathrm{k}_{\mathrm{PAR}}$ in the top $20 \mathrm{~m}$ of the water column varied seasonally with the highest $\mathrm{k}_{\mathrm{PAR}}$ values found in the summer and the lowest values in the fall and spring. Surface irradiance was about 2 orders of magnitude higher on full moon compared to new moon nights (Table 2).

Thermal conditions ranged from isothermal at $3.5^{\circ} \mathrm{C}$ in May 2004 and 2005 to a strongly stratified water column during the summer of 2004 and 2005. The depth of the thermocline (defined as the depth at which the rate of temperature change with increasing depth is maximized) ranged from $7 \mathrm{~m}$ in June, 2005 to $27 \mathrm{~m}$ in September, 2005 (Table 2).

\section{Mysid vertical distribution, length and abundance}

Mysid vertical distribution varied with moon phase. Mysids were consistently found deeper in the water column on full moon versus new moon nights, when temperature conditions were similar, i.e. when surface temperature was within $2^{\circ} \mathrm{C}$ and thermocline depth was within $5 \mathrm{~m}$ (Fig. 1, Table 2). Light levels at the peak of the mysid distribution were also consistently higher on full moon versus new moon nights, when temperature conditions were similar. We never found more than $10 \%$ of the population above $1 \times 10^{-7}$ mylux in any season.

Temperatures associated with the peak of the mysid layer during stratified conditions varied from $4.1^{\circ} \mathrm{C}$ in September 2004 to $6.4^{\circ} \mathrm{C}$ on August 16, 2004 (Table 2). Temperatures at the peak of the mysid distribution were significantly higher on new moon versus full moon nights during periods of thermal stratification (2-tailed $t$-test, $t=2.95, \mathrm{p}=0.04, \mathrm{n}_{\text {new }}=3, \mathrm{n}_{\text {full }}=3$ ).

Table 2. Light, temperature and depth representing the shallowest 10 and $90 \%$ of the mysid population as well as the peak of the mysid distribution. The thermocline depth is defined as the depth at which temperature change is fastest. Depth range of mysid layer: difference

\begin{tabular}{|c|c|c|c|c|c|c|c|c|c|c|c|c|c|c|c|}
\hline \multirow[t]{2}{*}{ Year } & \multirow[t]{2}{*}{ Date } & \multirow{2}{*}{$\begin{array}{l}\text { Moon } \\
\text { phase }\end{array}$} & \multicolumn{4}{|c|}{ Mysid layer depth (m) } & \multicolumn{5}{|c|}{ Light (mylux) } & \multicolumn{3}{|c|}{ Temperature $\left({ }^{\circ} \mathrm{C}\right)$} & \multirow{2}{*}{$\begin{array}{c}\text { Thermocline } \\
\text { depth }(\mathrm{m})\end{array}$} \\
\hline & & & $10 \%$ & Peak & $90 \%$ & Range & Surface & $10 \%$ & Peak & $90 \%$ & $\mathrm{k}_{\mathrm{PAR}}$ & Surface & $10 \%$ & Peak & \\
\hline \multirow[t]{4}{*}{2004} & 19 Мау & New & 25 & 45 & - & - & $5 \times 10^{-6}$ & $1 \times 10^{-7}$ & $9 \times 10^{-9}$ & - & 0.21 & 3.8 & 3.5 & 3.5 & - \\
\hline & 16 Aug & New & 25 & 30 & 46 & 21 & $5 \times 10^{-6}$ & $1 \times 10^{-8}$ & $6 \times 10^{-9}$ & $1 \times 10^{-9}$ & 0.32 & 21.0 & 9.3 & 6.4 & 21 \\
\hline & 27 Aug & Full & 30 & 36 & 53 & 23 & $1 \times 10^{-4}$ & $4 \times 10^{-7}$ & $2 \times 10^{-7}$ & $2 \times 10^{-8}$ & 0.24 & 21.5 & 5.6 & 4.5 & 19 \\
\hline & $30 \mathrm{Sep}$ & Full & 45 & 58 & - & - & $5 \times 10^{-4}$ & $2 \times 10^{-7}$ & $2 \times 10^{-8}$ & - & 0.13 & 17.4 & 4.1 & 4.1 & 15 \\
\hline \multirow[t]{4}{*}{2005} & 5 May & New & 26 & 46 & 53 & 27 & $5 \times 10^{-6}$ & $2 \times 10^{-7}$ & $3 \times 10^{-8}$ & $1 \times 10^{-8}$ & 0.16 & 3.6 & 3.5 & 3.5 & - \\
\hline & 20 Jun & Full & 24 & 29 & 36 & 12 & $2 \times 10^{-4}$ & $2 \times 10^{-7}$ & $8 \times 10^{-8}$ & $3 \times 10^{-8}$ & 0.21 & 18.5 & 6.2 & 5.0 & 7 \\
\hline & $7 \mathrm{Jul}$ & New & 21 & 24 & 30 & 9 & $5 \times 10^{-6}$ & $4 \times 10^{-8}$ & $2 \times 10^{-8}$ & $8 \times 10^{-9}$ & 0.23 & 21.7 & 6.9 & 5.5 & 19 \\
\hline & 27 Sep & New & 29 & 35 & 47 & 18 & $5 \times 10^{-6}$ & $2 \times 10^{-8}$ & $9 \times 10^{-9}$ & $1 \times 10^{-9}$ & 0.13 & 20.0 & 10.2 & 5.4 & 27 \\
\hline
\end{tabular}
between the depth of the shallowest 10 and $90 \%$ of the mysid distribution; $\mathrm{k}_{\mathrm{PAR}}$ : 0 to $20 \mathrm{~m}$ 


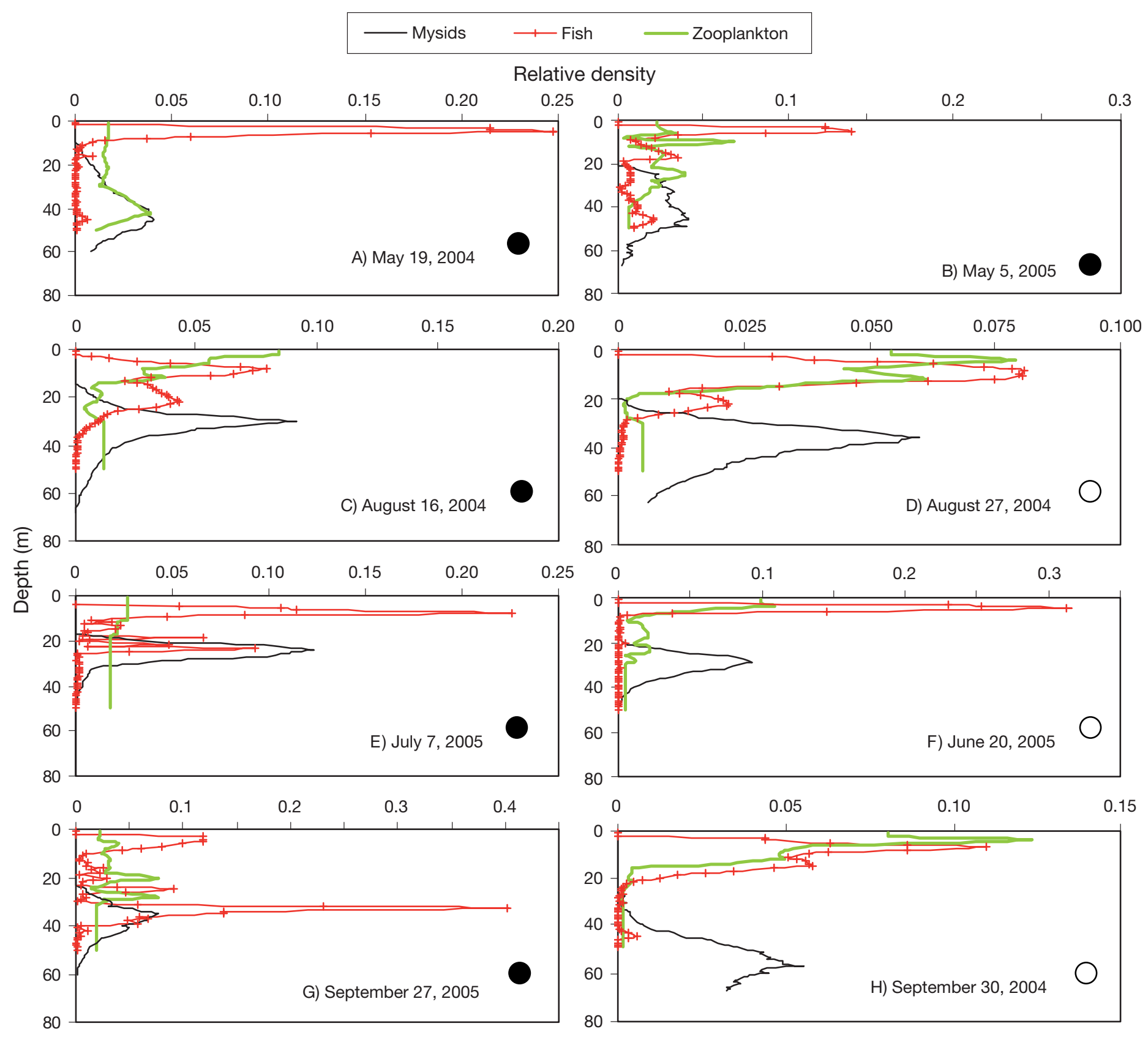

Fig. 1. Vertical distribution of mysids, zooplankton and fishes on 8 sampling nights on Lake Ontario. density for each profile equals 1 . Note the different $x$-axis scales

The peak of the mysid layer was significantly deeper during spring, when the lake was isothermal (May 2004, 2005), than during early summer (June and July 2005), when a shallow thermocline was present $(t=7.45, \mathrm{p}=$ 0.02). This was independent of moon phase. Furthermore, mysids were spread over a significantly larger range of depths during spring (mean depth range $=33 \mathrm{~m}$, $\mathrm{SE}=5.0$ ) than at all other times of the year for which data were available (mean depth range $=17 \mathrm{~m}, \mathrm{SE}=3.0$ ) $\left(t=3.0, \mathrm{p}=0.03, \mathrm{n}_{\text {spring }}=2, \mathrm{n}_{\text {other }}=5\right)$.
Mysid depth distributions obtained with the $430 \mathrm{kHz}$ unit were very similar to the depth distributions obtained with the $123 \mathrm{kHz}$ unit. For example, for the July 07, 2005 data, we found a highly significant relationship between mysid density estimates obtained with the 123 and $430 \mathrm{kHz}$ units $\left(\mathrm{r}^{2}=0.90\right.$, slope $=0.99$; evaluated for all depths between 20 and $50 \mathrm{~m}$ ) (see Rudstam et al. 2008b for detailed discussion).

Mean size of mysids ranged from a minimum of $8.0 \mathrm{~mm}$ on May 5, 2005 to a maximum of $11.4 \mathrm{~mm}$ on 
May 19, 2004 (Table 3). Mean abundance, as estimated through net tows, ranged from 71 mysids $\mathrm{m}^{-2}$ on September 27, 2005 to 801 mysids $\mathrm{m}^{-2}$ on July 7, 2005 (Table 3). Acoustically derived densities were somewhat lower than net tow estimates and ranged from 44 to 290 mysids $\mathrm{m}^{-2}$; however, no significant differences were found when acoustic and net tow estimates were compared across all dates in which net tows were taken (Paired $t$-test, $t=1.85, \mathrm{p}=0.11, \mathrm{n}=7$ ). The correlation between acoustic and net hauls in July 2005 using a larger data set was high $\left(\mathrm{r}^{2}=0.68\right.$; Rudstam et al. 2008b).

\section{Fish vertical distribution, length and abundance}

Fish vertical distribution tended to be bimodal when the lake was thermally stratified, with a large peak in the epilimnion and a smaller peak in the metalimnion. The upper peak tended to coincide with high zooplankton biomass in epilimnetic waters and the lower peak with the upper edge of the mysid layer in metalimnetic waters (Fig. 1). An exception to this bimodal pattern during stratified conditions occurred in June 2005, when there was only one epilimnetic peak between 5 and $10 \mathrm{~m}$, which coincided with the zooplankton peak.

Fishes were found deepest in the water column in May 2005. On this sampling date, fishes had a bimodal distribution with one peak between 45 and $50 \mathrm{~m}$ (which coincided with the peak of the mysid distribution), and a shallower peak between 8 and $10 \mathrm{~m}$, which coincided with the zooplankton peak (Fig. 1). We did not observe a bimodal distribution in May 2004, when there was only one peak between 8 and $10 \mathrm{~m}$ (Fig. 1).

We did not notice any effects of moon phase on the vertical distribution of fishes. The depth of the main peak was nearly identical during new and full moons in August 2004 and in June (full) and July (new) 2005. Fish distributions were quite different in the September new moon-full moon comparison, but this was likely due to the higher contribution of rainbow smelt below the thermocline in 2005 (see below).

Fish abundance estimates near our $170 \mathrm{~m}$ sampling station in 2004 ranged from 462 ind. ha ${ }^{-1}$ on August 16 to 5761 ind. ha ${ }^{-1}$ on September 30 (Table 3). The majority of these fishes were found in the upper epilimnion, as total abundance dropped sharply below the thermocline. Abundance estimates were significantly lower in 2005 (range $=36$ ind. ha ${ }^{-1}$ in July to 462 ind. $\mathrm{ha}^{-1}$ in May), and a larger proportion were found below the thermocline than in 2004. Gillnet and trawl catch through the mysid layer indicated that nearly $100 \%$ of the fishes sampled through the mysid layer were alewives on 5 of the 6 nights in which fish sampling was conducted (mean fish length $=162 \mathrm{~mm}$,

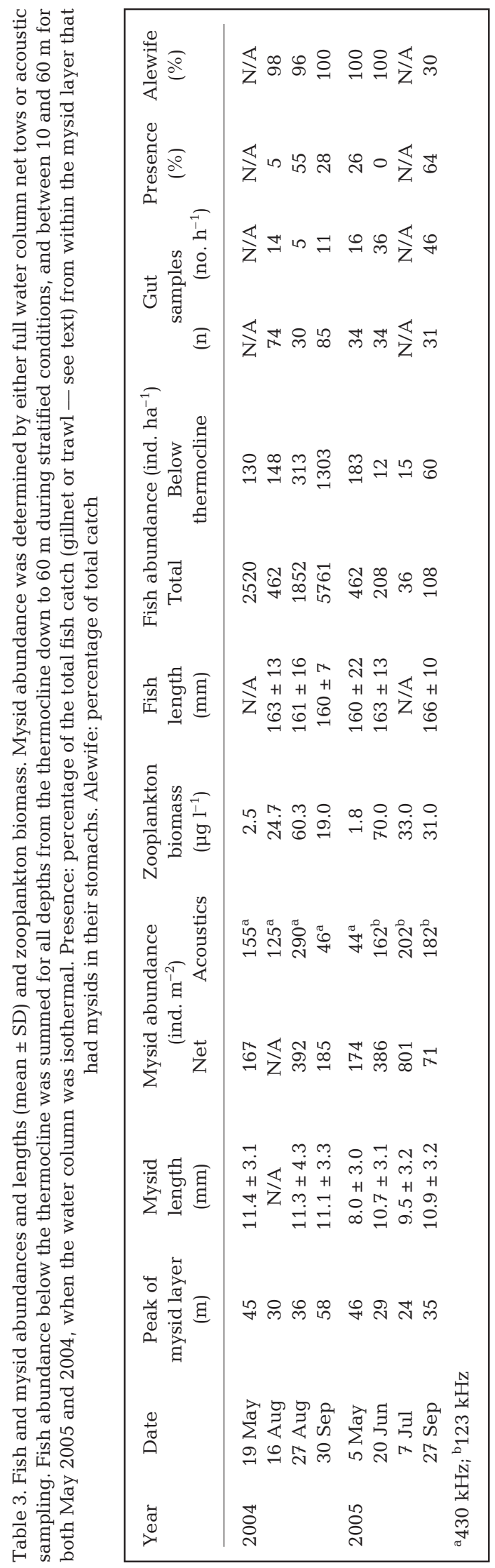


range of sizes $=50$ to $190 \mathrm{~mm}$; Table 3 ). These results confirm that alewives frequently occur within the mysid layer during all 3 seasons. Gut content analyses confirmed that alewives and smelt were feeding on mysids on all nights sampled, with the exception of June 20, 2005 (Table 3).

We saw no consistent patterns in alewife length by depth on any of the sampling nights in which gillnets were used and no differences in mean alewife length on June 20, 2005 among fishes caught in and above the mysid layer. These results indicate that alewives were not segregated by size within the mysid layer (i.e. between 15 and $35 \mathrm{~m}$ ) and were not segregated in epilimnetic waters at night during June 2005. The one exception to alewives dominating our gillnet and midwater trawl catches occurred in September, 2005, when over half of the trawl catch through the mysid layer (22 to $60 \mathrm{~m}$ ) was rainbow smelt. It was during this time period that a larger proportion of the fish backscattering occurred below the thermocline, relative to the other sampling nights (Fig. 1, Table 3). We assume that the fish in this deeper layer in September 2005 were primarily rainbow smelt, while fish caught above the thermocline $(<27 \mathrm{~m})$ were primarily adult and juvenile alewives (see discussion in Gal et al. 2006). Because so few alewives were caught in our trawls in September, 2005, we cannot draw conclusions about segregation of alewife age classes on this date.

\section{Zooplankton vertical distribution and total biomass}

Zooplankton vertical distributions varied seasonally and by moon phase. Zooplankton biomass generally peaked in the top $10 \mathrm{~m}$ of the water column and dropped off considerably at depths below the thermocline (Fig. 1). One notable exception was September 2005 when the thermocline was at $27 \mathrm{~m}$ and there was a substantial Limnocalanus peak below it. Results from net tows below $30 \mathrm{~m}$ in 2005 suggest that zooplankton biomass remains low and relatively constant in hypolimnetic waters (biomass estimates in the 30 to $40 \mathrm{~m}$ depth stratum were nearly identical to estimates in the 40 to $50 \mathrm{~m}$ stratum for all nights in 2005). Zooplankton biomass peaks were slightly deeper in the spring (Fig. 1). Mean zooplankton biomass down to $30 \mathrm{~m}$ depth was 11 to 32 fold higher during summer than during spring and varied nearly 3 fold during June to August (Table 3). Mean biomass in September 2005 was about $60 \%$ higher than in September 2004 .
Comparisons of our net and pump samples failed to show any significant differences between the 2 techniques. Estimates for mean zooplankton biomass down to $22 \mathrm{~m}$ were identical between the 2 techniques $(26 \mu \mathrm{g}$ $\mathrm{l}^{-1}$ ) and species composition of the integrated samples was also similar (percent biomass ratios for pump:net = 41:42 for cyclopoids, 31:39 for calanoids, 17:9 for Bythotrephes spp., 9:5 for Daphnia spp., 2:5 other).

\section{Model performance}

Temperature-light model (TLM)

The TLM predicted the peak of the mysid distribution to within $5 \mathrm{~m}$ on 7 of the 8 nights sampled, and within $10 \mathrm{~m}$ in May 2004. Overlap between TLM predictions and observed mysid distributions was $>74 \%$ on all sampling nights (84\% on August 16, 2004), indicating that the model is a good predictor of both the peak and range of the mysid distribution in the field (Fig. 2, Table 4).

\section{Growth $(g)$ model}

The model based on mysid growth at depth predicted the peak of the mysid layer to within $10 \mathrm{~m}$ on 3 of the 8 nights, but vastly underestimated the observed peak in May 2005 (Fig. 3, Table 4). Overlap between growth model predictions and observed mysid distributions ranged from $39 \%$ in May 2005 to $79 \%$ in September 2005. There were no significant differences in percent overlap (2-tailed $t$-test, $t=0.14, \mathrm{p}=0.19$ ) or difference from observed peak ( $t=0.81, \mathrm{p}=0.45$ ) predictions when means were compared on new moon versus full moon nights $\left(\mathrm{n}_{\text {new }}=5, \mathrm{n}_{\text {full }}=3\right)$, or between stratified $\left(\mathrm{n}_{\text {strat }}=6\right)$ and isothermal $\left(\mathrm{n}_{\mathrm{iso}}=2\right)$ conditions

Table 4. Comparison of the mysid temperature-light (TLM), growth $(g)$ and growth:mortality risk $(g: \mu)$ models to observed mysid distribution. Means with different superscript letters are significantly different (pairwise comparisons with Tukey-Kramer HSD post-hoc test; $\alpha=0.05$ )

\begin{tabular}{|lcccccccc|}
\hline \multirow{2}{*}{ Year } & \multirow{2}{*}{ Date } & \multicolumn{3}{c}{ Peak } & \multicolumn{3}{c}{ Difference from peak (m) } & \multicolumn{3}{c|}{ Overlap $(\%)-$} \\
& & $(\mathrm{m})$ & TLM & $g$ & $g: \mu$ & TLM & $g$ & $g: \mu$ \\
\hline 2004 & 19 May & 45 & 9 & 2 & 18 & 80 & 68 & 65 \\
& 16 Aug & 30 & 0 & 19 & 20 & 84 & 68 & 22 \\
& 27 Aug & 36 & 5 & 13 & 13 & 76 & 75 & 49 \\
& 30 Sep & 58 & 3 & 9 & 8 & 75 & 53 & 48 \\
2005 & 5 May & 46 & 0 & 36 & 15 & 75 & 39 & 45 \\
& 20 Jun & 29 & 1 & 5 & 7 & 74 & 52 & 22 \\
& 7 Jul & 24 & 2 & 26 & 25 & 76 & 39 & 12 \\
\multirow{2}{*}{ Mean } & 27 Sep & 35 & 1 & 15 & 12 & 78 & 79 & 28 \\
SE & - & - & $2.6^{\mathrm{A}}$ & $15.6^{\mathrm{B}}$ & $14.8^{\mathrm{B}}$ & $77.2^{\mathrm{A}}$ & $59.0^{\mathrm{B}}$ & $36.4^{\mathrm{C}}$ \\
& - & - & 1.1 & $4.0^{2}$ & 2.1 & 1.2 & 5.5 & 6.4 \\
\hline
\end{tabular}




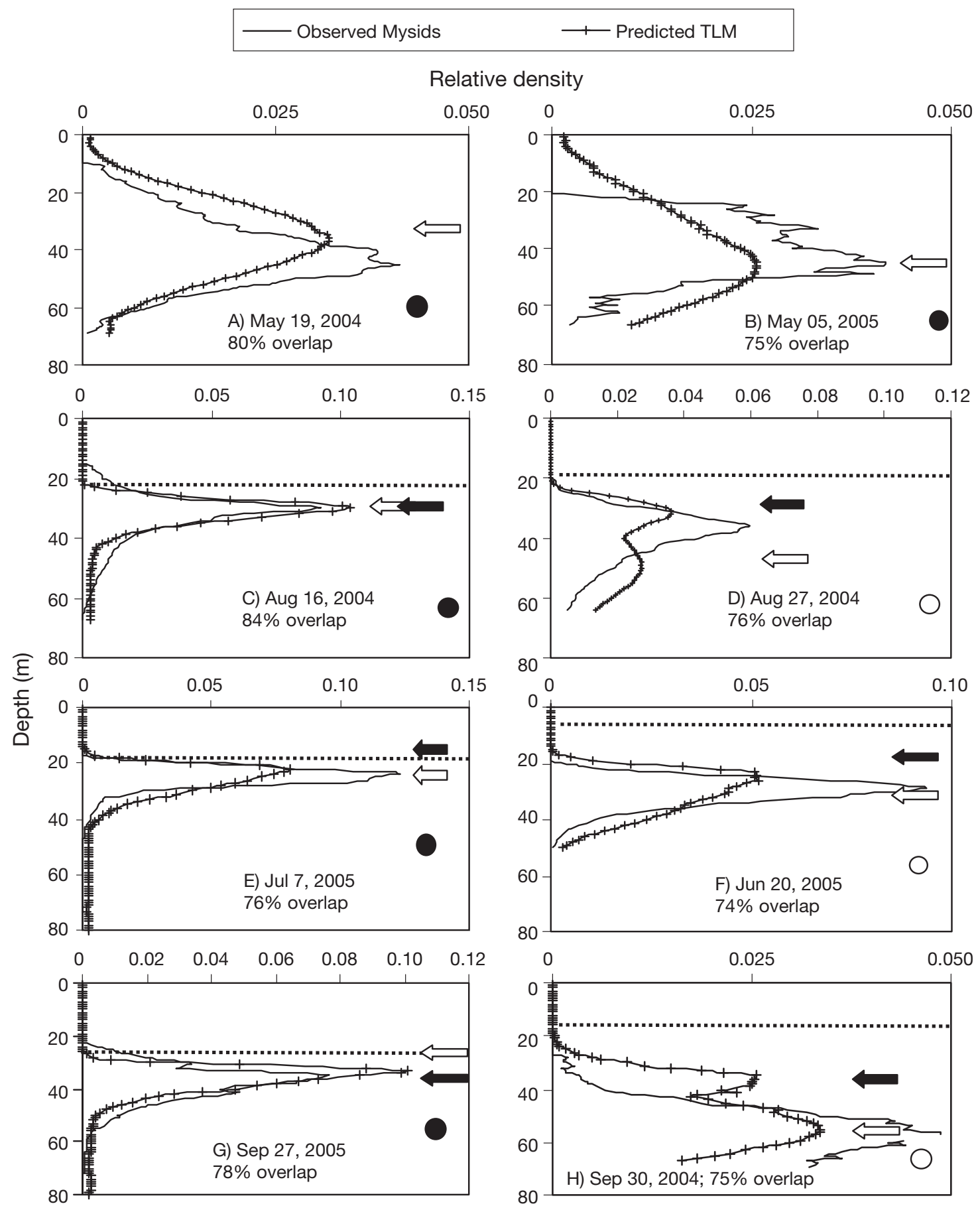

Fig. 2. Observed mysid distributions versus temperature-light model (TLM) predictions during full moon (O) and new moon $(\mathbf{0})$ nights. Dashed line: thermocline. May profiles were isothermal. Black arrows: depth at which the temperature preference function is maximized; open arrows: depth at which the light preference function is maximized. Total density for each profile equals 1.

Note the different $x$-axis scales

( $p>0.50$ when both percent overlap and differences from observed peak means were compared). These results indicate that the growth model was not a better predictor of mysid distribution under any particular light or seasonal temperature conditions.

\section{Growth:mortality risk $(g: \mu)$ model}

The $g: \mu$ model predicted the peak of the mysid distribution to within $10 \mathrm{~m}$ on only 2 of the 8 nights sampled (Table 4). Overlap ranged from $12 \%$ in July 2005 to 


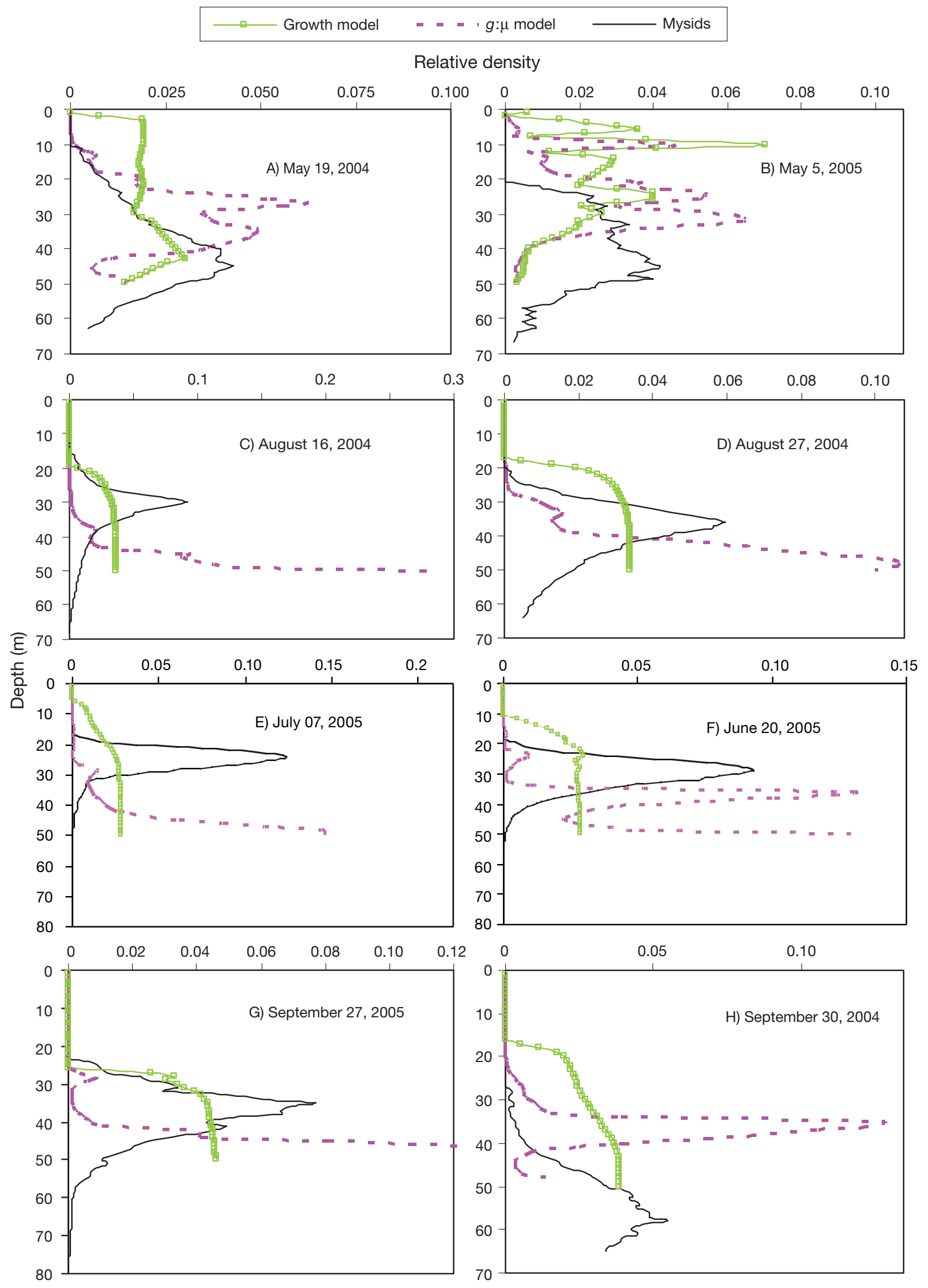

Fig. 3. Observed and predicted mysid distributions for the growth model and the growth:mortality risk $(g: \mu)$ model 
$65 \%$ in May 2004, and was not significantly higher during the spring, isothermal months than during stratified conditions (2-tailed $t$-test, $t=0.43, \mathrm{n}_{\text {spring }}=2$, $\mathrm{n}_{\text {stratified }}=6, \mathrm{p}=0.68$ ) or on new moon versus full moon nights $\left(t=0.17, \mathrm{n}_{\text {new }}=5, \mathrm{n}_{\text {full }}=3, \mathrm{p}=0.87\right)$.

\section{Comparison of all models}

The TLM was a significantly better predictor of the depth of peak mysid density (Table $4 ; 1$-way ANOVA, $F_{2,21}=8.2, \mathrm{p}=0.002$ ) and the range of depths occupied by the mysid layer, as approximated by percent overlap $\left(F_{2,21}=14.2, \mathrm{p}<0.0001\right)$ than either the growth or $g: \mu$ models, when the respective mean values were compared across all dates. Tukey-Kramer HSD posthoc tests (JMP Version 5.1) revealed significant differences between all 3 models in terms of mean percent overlap (TLM $>g>g$ : $\mu$; all $\mathrm{p}<0.02$ ), but between the TLM and growth model and the TLM and $g: \mu$ model only when comparing difference from peak means $(g>$ $g: \mu>\mathrm{TLM}_{\text {; }}$ for $g$ to $g: \mu, \mathrm{p}=0.84$; for TLM to $g, \mathrm{p}=$ 0.0020 , for TLM to $g: \mu, p=0.0027$ ).

\section{DISCUSSION}

We show that a model based on 2 readily measured environmental factors, temperature and light, provides reasonable predictions of the entire nighttime distribution of mysids during the spring, summer and fall in Lake Ontario. In contrast, the models based on estimated growth rate and on the ratio of growth rate to predation risk did not accurately predict the depth of maximum mysid density or the range of depths occupied by mysids (less overlap between predicted and observed distributions). We conclude that the response to temperature and light alone is sufficient for predicting mysid vertical distribution across seasons in Lake Ontario.

\section{Abundance estimates}

We do not think that our mysid acoustic returns were biased due to backscattering contributions of other species. Net samples taken above, through, and below the mysid layer confirmed acoustic returns in both 2004 and 2005, with greater than $85 \%$ of the catch occurring at depths deemed to be the 'mysid scattering layer' (as determined through visual inspection of acoustic echograms) on all dates. Estimates were likely not confounded by smaller zooplankton, as invertebrates $<4 \mathrm{~mm}$ are weak scatterers and likely do not contribute substantially to backscattering in the mysid layer (see Rudstam et al. 2008b). In addition, very few juvenile fishes were found within the mysid layer in our gillnets; this should decrease the probability of including fish scattering in our mysid distribution analyses.

Differences in absolute mysid and fish abundance between years were likely due to sampling variance, given that we only surveyed a relatively small region of the lake. These estimates should therefore not be extrapolated to lake-wide abundances and we present them only as a means of describing densities near our $170 \mathrm{~m}$ sampling station. Our abundance estimates for mysids are reasonable, compared to literature estimates at similar times of the year (Johannsson et al. 2003). Fish density at our sampling station, however, was lower on all but one date than the mean alewife density in Lake Ontario. In 2004 and 2005, numbers of alewives in the USA sector of the lake averaged 4329 ind. ha ${ }^{-1}$, as estimated from area swept by bottom trawls in early spring, when alewives are close to bottom (R. O'Gorman, unpublished data). The lower fish densities at our station are not surprising, given that there are large differences in alewife density along the southern shoreline in early spring, and the geographic region with peak density varies from year to year, suggesting that alewives are highly mobile. Moreover, alewives move seasonally between off-shore and nearshore, migrating nearshore in spring and spawning there in summer.

\section{Comparison of model predictions}

We never found more than $10 \%$ of the mysid population at depths with $>10^{-7}$ mylux, regardless of moon phase, depth of the thermocline, or relative predator and prey abundances. These results indicate that mysids do not move into light levels $>10^{-7}$ mylux, even if abundant food is available in brighter light. This is similar to earlier observations in Lake Ontario (Gal et al. 1999, 2004) and elsewhere (Janssen \& Brandt 1980, Moen \& Langeland 1989, Rudstam et al. 1989). However, mysids were found deeper (and thus at lower temperatures) on full moon nights and at slightly higher light levels than the light preference function alone would predict on nights with shallow thermoclines. Despite these substantial differences in temperature and light preference predictions on some nights, the TLM was able to predict the depth of peak mysid density to within $10 \mathrm{~m}$ on all sampling occasions and to within $3 \mathrm{~m}$ on 6 of the 8 nights we sampled. These results support our light and temperature preference functions and indicate that the model, which assumes that light and temperature functions are independent and have equal weight, yields reasonably accurate 
predictions of distribution even when light and temperature functions predict peak depth distributions several meters apart.

Although we did not test the models in the winter, the ability of the TLM to predict both the range and peak depths occupied by the mysid layer across such a wide variety of environmental conditions from spring to late fall shows that mysid distribution can be predicted based on temperature and light alone during most of the year. This result is somewhat surprising, given that the light and temperature preference functions were derived based on adult mysid behavior only. Juvenile mysids are typically found higher in the water column than adults (Grossnickle \& Morgan 1979, Bowers 1988, Rudstam et al. 1989), indicating that smaller mysids may have higher light and temperature tolerances than larger mysids. An alternative explanation is that our acoustic sampling procedure did not accurately detect smaller mysids. Mysids $<7 \mathrm{~mm}$ made up a large proportion of the overall mysid catch in May through July 2005, suggesting a large brood release in spring 2005. Given that small mysids are relatively weak scatterers, they will contribute less to the overall mysid backscattering than adult individuals (Rudstam et al. 2008b). However, we were able to accurately predict both the range and peak of mysid vertical distribution in Lake Ontario for most of the sampling nights, suggesting that mysid size differences may not be playing a large role in structuring the overall distribution.

There are several potential explanations as to why both the growth and the $g: \mu$ models were not as strong predictors of mysid distribution as the TLM. We did not have zooplankton biomass data through the peak of the mysid layer on several occasions in 2004 (August 16, August 27 and September 30), and on those sampling dates we assumed that zooplankton biomass in the mysid layer was the same as at the deepest sampled depth of $30 \mathrm{~m}$. This assumption was supported by our data collected in May, June, July and September 2005, when zooplankton was sampled down to $50 \mathrm{~m}$ depth (through at least $90 \%$ of the mysid layer on these nights). Even if we exclude the 3 profiles in 2004 for which we do not have zooplankton data down to $50 \mathrm{~m}$, the TLM was a better predictor of peak mysid density than either the growth or $g: \mu$ models. However, the observed mysid distribution in September 2004 was several meters deeper than the $50 \mathrm{~m}$ depth limit of the growth and $g: \mu$ models, and this made it impossible to accurately predict the actual depth of peak mysid density on this date. If we assume similarly low zooplankton densities past $50 \mathrm{~m}$ on this date (as we assumed between 30 and $50 \mathrm{~m}$ ), the model would still predict the peak of the mysid distribution to be $8 \mathrm{~m}$ shallower than was observed.
It is unlikely that zooplankton peaks in the 30 to $50 \mathrm{~m}$ depth stratum would be significant enough to alter our predictions of the depth of maximum growth. Zooplankton densities are typically very low below the thermocline in Lake Ontario (Johannsson et al. 1994, Gal et al. 2006) and remain at constant, low-density levels below $30 \mathrm{~m}$ (see Benoit et al. 2002 for discussion). Given (1) that the thermocline was shallower than $30 \mathrm{~m}$ in all 8 profiles, and (2) the similarity in zooplankton density estimates in the 40 to $50 \mathrm{~m}$ and 30 to $40 \mathrm{~m}$ stratified net tows in 2005, we do not think that there would have been a substantial peak in zooplankton density below $30 \mathrm{~m}$ that is correlated with the mysid peak; however, we cannot exclude this possibility, and future investigations may provide further insight into the prevalence and importance of deep zooplankton layers on mysid behavior.

One possible explanation for why the $g: \mu$ model did not provide better predictions of mysid distribution is that predation risk may be better approximated with a model based on reaction distance or feeding rate, rather than a model based on the product of predator abundance and proportion of fishes that are feeding. Batty et al. (1990) based their estimates of the proportion of fishes that are feeding entirely on the number of fishes displaying feeding-oriented swimming behavior, and they did not measure capture success or feeding rate. However, it is possible that the proportion of fishes engaged in feeding-oriented swimming behavior does not translate proportionally into foraging success. For example, alewives may switch between different types of searching behavior, depending on the light level present, particularly given that alewives are capable of feeding in complete darkness, using lateral line sensitivity (Janssen et al. 1995).

Another possible explanation why the growth and $g: \mu$ models were not better predictors of mysid distribution relates to the main assumption of both modelsthat mysid distribution is directly proportional to growth or growth:mortality risk. Lampert et al. (2003) reported that Daphnia pulex $\times$ galeata were distributed vertically in experimental plankton towers in direct proportion to their growth profiles. They described the resulting distribution as approximating an ideal free distribution, given known concentrations of (and predicted gains and losses associated with) food and temperature at $1 \mathrm{~m}$ depth intervals in the water column. A true ideal free distribution, however, assumes that organisms select habitat in proportion to the supply rate of resources, so that each animal receives identical food resources regardless of their location. Lampert et al. (2003) argued that in filter-feeding daphnids, feeding rate is directly related to food concentration, and therefore that a relatively constant food gradient (owing to daily replenishment) should mimic a con- 
stant supply rate. However, these assumptions may not hold for mysids in the same way as they do for filterfeeding daphnids.

\section{Implications}

We are not implying that mysid distributions are unaffected by predators and prey. Our results suggest that mysid distribution is best approximated by absolute light and temperature preferences, but these preferences likely evolved as mechanisms to increase food intake during periods of low predation risk. Constantly searching for the exact optimum depth that would maximize $g: \mu$ (i.e. displaying direct responses to relative prey and predator abundances over a short time period) may be too risky for $M$. diluviana. Mysids have slow growth rates, long generation times and low life-time fecundity, which should lead to a strong selection for avoiding predators by staying in colder and darker waters. $r$-selected species with high clearance rates, such as daphnids, can more effectively exploit higher prey concentrations over short time periods in shallow waters, and this could explain why daphnids are more plastic in their depth selection than mysids.

The ability to model entire distributions of a migrating population based on relatively simple parameters, such as light and temperature, has important ecological and management implications. The success of the TLM in predicting mysid distribution across 3 different seasons and 2 different moon phases suggests that we should be able to forecast distributional shifts resulting from long-term environmental changes such as global warming or increased light penetration, observed in Lake Ontario and other North American lakes (Anderson et al. 1996, Magnuson et al. 2000, Mills et al. 2003). Similar models have been used to forecast impacts of climate change on vertical and horizontal distributions of migrating organisms (DeStasio et al. 1996, McDonald et al. 1996, Schindler et al. 2005). Given the direct link between mysids, alewife and salmonids, the ability to predict vertical distributions also has important implications for both the current and future management of salmonid fisheries in the Great Lakes and other systems inhabited by both mysids and salmonids.

This study also provides one of the first accounts of a bimodal distribution of alewives in the pelagic waters of Lake Ontario-with an upper peak that appears to coincide with the main zooplankton layer and another, deeper peak which overlaps with the upper edge of the mysid layer. By extension, we demonstrate that much of the interaction between mysids and their fish predators and zooplankton prey is occurring at the upper edge of the mysid distribu- tion. If an assessment of the contribution of mysids to the pelagic food web were based on the 'average' mysid alone, we would underestimate the significance of mysid feeding and their availability as a food resource to alewives over the deeper waters of the lake during thermal stratification.

Acknowledgements. This research was funded by New York Sea Grant project R/CE-23, with additional funding by the Cornell University Agricultural Experiment Station federal formula funds Project NYC147419, received from Cooperative State Research, Education and Extension Service, US Department of Agriculture. The views expressed are those of the authors and do not necessarily reflect the views of NOAA or USDA. The US Government is authorized to produce and distribute reprints for governmental purposes notwithstanding any copyright notation that may appear herein. We thank the crew aboard the USGS RV 'Kaho', Kelly Bowen, Jim Watkins, Ed Mills and Gideon Gal for assistance with the field work. We also extend special thanks to the interns of the Cornell Biological Field Station Summer Internship Program, especially Jill Tirabassi, Tyson Buerkle, Christine Chu, Emily Freund and Shylene Mata. This is contribution \#265 of the Cornell Biological Field Station and contribution 1526 of the USGS Great Lakes Science Center.

\section{LITERATURE CITED}

Anderson WL, Robertson DM, Magnuson JJ (1996) Evidence of recent warming and El Niño-related variations in ice breakup of Wisconsin lakes. Limnol Oceanogr 41:815-821

Audzijonyte A, Väinölä R (2005) Diversity and distributions of circumpolar fresh- and brackish-water Mysis (Crustacea: Mysida): descriptions of $M$. relicta Lovén, 1862, M. salemaai n. sp., M. segerstralei n. sp. and M. diluviana n. sp., based on molecular and morphological characters. Hydrobiologia 544:89-141

Austin RH, Phillips BF, Webb DJ (1976) Method for calculating moonlight illuminance at Earth's surface. J Appl Ecol 13:741-748

> Batty RS, Blaxter JHS, Richard JM (1990) Light intensity and the feeding behavior of herring, Clupea harengus. Mar Biol 107:383-388

> Beeton AM, Bowers JA (1982) Vertical migration of Mysis relicta Lovén. Hydrobiologia 93:53-61

Benoit HP, Johannsson OE, Warner DM, Sprules WG, Rudstam LG (2002) Assessing the impact of a recent predatory invader: the population dynamics, vertical distribution, and potential prey. Limnol Oceanogr 47:626-635

Boscarino BT, Rudstam LG, Mata S, Gal G, Johannsson OE, Mills EL (2007) The effects of temperature and predatorprey interactions on the migration behavior and vertical distribution of Mysis relicta. Limnol Oceanogr 52:1599-1613

Boscarino BT, Rudstam LG, Loew ER, Mills EL (2009) Behavioral responses of the opossum shrimp, Mysis relicta, to different intensities of light and light-temperature combinations. Can J Fish Aquat Sci 66:101-113

Bowers JA (1988) Diel vertical migration of the opossum shrimp, Mysis relicta, in Lake Superior: observations and sampling from the Johnson-Sea-Link II submersible. Bull Mar Sci 43:730-738

Chipps SR, Bennett DH (2002) Evaluation of a Mysis bioenergetics model. J Plankton Res 24:77-82 
Cooper SD, Goldman CR (1980) Opossum shrimp (Mysis relicta) predation on zooplankton. Can J Fish Aquat Sci 37:909-919

DeStasio BT, Hill DK, Kleinhans JM, Nibbelink NP, Magnuson JJ (1996) Potential effects of global climate change on small north-temperate lakes: physics, fish, and plankton. Limnol Oceanogr 41:1136-1149

Feinsinger P, Spears EE, Poole RW (1981) A simple measure of niche breadth. Ecology 62:27-32

Fiksen O (1997) Allocation patterns and diel vertical migration: modeling the optimal Daphnia. Ecology 78:1446-1456

Fretwell SD, Lucas HL (1969) On territorial behavior and other factors influencing habitat distribution in birds. Acta Biotheor 19:16-36

Gal G, Loew ER, Rudstam LG, Mohammadian AM (1999) Light and diel vertical migration: spectral sensitivity and light avoidance by Mysis relicta. Can J Fish Aquat Sci 56: 311-322

Gal G, Rudstam LG, Johannsson OE (2004) Predicting Mysis relicta vertical distribution in Lake Ontario. Arch Hydrobiol 159:1-23

Gal G, Rudstam LG, Mills EL, Lantry JR, Johannsson OE, Greene CH (2006) Mysid and fish zooplanktivory in Lake Ontario: quantification of direct and indirect effects. Can J Fish Aquat Sci 63:2734-2747

Gliwicz ZM, Pijanowska J (1988) Effect of predation and resource depth distribution on vertical migration of zooplankton. Bull Mar Sci 43:695-709

Grossnickle NE, Morgan MD (1979) Density estimate of Mysis relicta in Lake Michigan. J Fish Res Bd Can 36:694-698

Hamrén U, Hansson S (1999) A mysid shrimp (Mysis mixta) is able to detect the odour of its predator (Clupea harengus). Ophelia 51:187-191

Hansson S, DeStasio BT, Gorokhova E, Mohammadian MA (2001) Ratio-dependent functional responses - tests with the zooplanktivore Mysis mixta. Mar Ecol Prog Ser 216: $181-189$

Hays GC (2003) A review of the adaptive significance and ecosystem consequences of zooplankton diel vertical migrations. Hydrobiologia 503:163-170

Janiczek PM, DeYoung JA (1987) Computer programs for sun and moon illuminance with contingent tables and diagrams. US Naval Observatory Circular 171, Washington DC

Janssen J (1990) Alewives (Alosa pseudoharengus) and ciscoes (Coregonus artedii) as selective and non-selective planktivores. In: Kerfoot WC (ed) Evolution and ecology of zooplankton communities. The University Press of New England, Hanover, NH, p 580-586

Janssen J, Brandt SB (1980) Feeding ecology and vertical migration of adult alewives (Alosa pseudoharengus) in Lake Michigan. Can J Fish Aquat Sci 37:177-184

> Janssen J, Jones WR, Whang A, Oshel PE (1995) Use of the lateral line in particulate feeding in the dark by juvenile alewife (Alosa pseudoharengus). Can J Fish Aquat Sci 52: 358-363

> Jensen OP, Hrabik TR, Martel SJD, Walters CJ, Kitchell JF (2006) Diel vertical migration in the Lake Superior pelagic community. II. Modeling tradeoffs at an intermediate trophic level. Can J Fish Aquat Sci 63:2296-2307

Jerome JH, Bukata RP, Bruton JE (1983) Spectral attenuation and irradiance in the Laurentian Great Lakes. J Gt Lakes Res 9:60-68

Johannsson OE, Shaw MA, Yan ND, Filion JM, Malley DF (1992) A comparison of freshwater sampling gear: nets, trap and submersible pump. Can Tech Rep Fish Aquat Sci 1894, p 1-29
Johannsson OE, Rudstam LG, Lasenby DC (1994) Mysis relicta: assessment of a metalimnetic feeding strategy and implications for competition in Lakes Ontario and Michigan. Can J Fish Aquat Sci 51:2591-2602

Johannsson OE, Rudstam LG, Gal G, Mills EL (2003) Mysis relicta in Lake Ontario: population dynamics, trophic linkages and further questions. In: Munawar M (ed) State of Lake Ontario-past, present and future. EcovisionWorld Monograph Series, Burlington, p 257-287

Korneliussen RJ (2000) Measurement and removal of echo integration. ICES J Mar Sci 57:1204-1217

Lampert WE (1993) Ultimate causes of diel vertical migration of zooplankton: new evidence for the predator-avoidance hypothesis. Arch Hydrobiol Beih Ergebn Limnol 39:79-88

Lampert WE, McCauley E, Manly BFJ (2003) Trade-offs in the vertical distribution of zooplankton: ideal free distribution with costs? Proc R Soc Lond B Biol Sci 270:765-773

$>$ Larsson P (1997) Ideal free distribution in Daphnia? Are daphnids able to consider both the food patch quality and the position of competitors? Hydrobiologia 360:143-152

- Lindström M, Nilsson HL (1988) Eye function of Mysis relicta Lovén (Crustacea) from two photic environments: spectral sensitivity and light tolerance. J Exp Mar Biol Ecol 120: 23-37

> Liu SH, Sun S, Han BP (2003) Diel vertical migration of zooplankton following optimal food intake under predation. J Plankton Res 25:1069-1077

> Magnuson JJ, Robertson DM, Benson BJ, Wynne RH and others (2000) Historical trends in lake and river ice cover in the Northern Hemisphere. Science 289:1743-1746

Masson S, Pinel-Alloul B, Méthot G, Richard N (2004) Comparison of nets and pump sampling gears to assess zooplankton vertical distribution in stratified lakes. J Plankton Res 26:1199-1206

McDonald ME, Hershey AE, Miller MC (1996) Global warming impacts on lake trout in arctic lakes. Limnol Oceanogr 41:1102-1108

Mills EL, O'Gorman R, Degisi J, Heberger RF, House RA (1992) Food of the alewife (Alosa pseudoharengus) in Lake Ontario before and after the establishment of Bythotrephes cederstroemi. Can J Fish Aquat Sci 49:2009-2019

Mills EL, Casselman JM, Dermott R, Fitzsimons JD and others (2003) Lake Ontario: food web dynamics in a changing ecosystem (1970-2000). Can J Fish Aquat Sci 60:471-490

> Moen V, Langeland A (1989) Diurnal vertical and seasonal horizontal distribution patterns of Mysis relicta in a large Norwegian lake. J Plankton Res 11:729-745

Morgan MD (1976) Life history and annual net secondary productivity of Mysis relicta Lovén in west central Lake Michigan. MS thesis, University of Wisconsin, Milwaukee, WI

Owens RW, O'Gorman R, Eckert TH, Lantry BF (2003) The offshore fish community in southern Lake Ontario, 1972-1998. In: Munawar M (ed), State of Lake Ontariopast, present and future. EcovisionWorld Monograph Series, p 407-442.

$>$ Rand PS, Lantry BF, O'Gorman R, Owens RW, Stewart DJ (1994) Energy density and size of pelagic prey fishes in Lake Ontario (1978-1990) -implications for salmonine energetics. Trans Am Fish Soc 123:519-534

> Rudstam LG (1989) A bioenergetics model for Mysis growth and consumption applied to a Baltic population of Mysis mixta. J Plankton Res 11:971-983

> Rudstam LG, Danielsson K, Hansson S, Johansson S (1989) Diel vertical migration and feeding patterns of Mysis mixta (Crustacea, Mysidacea) in the Baltic Sea. Mar Biol 101:43-52 
Rudstam LG, Hetherington AL, Mohammadian AM (1999) Effect of temperature on feeding and survival of Mysis relicta. J Gt Lakes Res 25:363-371

> Rudstam LG, Knudsen FR, Balk H, Gal G, Boscarino BT, Axenrot T (2008a) Acoustic characterization of Mysis relicta at different frequencies. Can J Fish Aquat Sci 65: $2769-2779$

Rudstam LG, Schaner T, Gal G, Boscarino BT and others (2008b) Hydroacoustic measures of Mysis relicta abundance and distribution in Lake Ontario. Aquat Ecosyst Health Manage 11:355-367

Scheuerell MD, Schindler DE (2003) Diel vertical migration by juvenile sockeye salmon: empirical evidence for the antipredation window. Ecology 84:1713-1720

Submitted: May 16, 2008; Accepted: April 15, 2009
Schindler DE, Rogers DE, Scheuerell MD, Abrey CA (2005) Effects of changing climate on zooplankton and juvenile sockeye salmon growth in southwestern Alaska. Ecology 86:198-209

Warner DM, Rudstam LG, Klumb RA (2002) In situ target strength of alewives in freshwater. Trans Am Fish Soc 131:212-223

Warner DM, Rudstam LG, Benoit H, Mills EL, Johannsson OE (2006) Changes in seasonal nearshore abundance patterns in Lake Ontario following establishment of the exotic predator Cercopagis pengoi. J Gt Lakes Res 32:531-542

Werner EE, Gilliam JF (1984) The ontogenetic niche and species interactions in size structured populations. Annu Rev Ecol Syst 15:393-425

Proofs received from author(s): May 17, 2009 